\title{
LA EDUCACIÓN ÉTICA EN EL SIGLO XXI
}

\section{Carmen Rosa Villarán Rodrigo*}

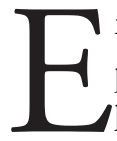

n nuestra época es muy común y está muy bien visto hablar de ética; pero en tanto se concibe a la ética como una realidad exigente para la conducta humana, se acaba por rechazarla, para quedarse con la diversión y múltiples ismos, que dan la espalda a la realidad de la ética para la vida. Además, suele confundirse placer con felicidad y tener con ser, como parecer con ser. Así, en esta época de facilidades para consumir, se insta al despliegue sin freno ni trabas de los gustos que se desean y se ofrecen como parte de la vida del inmediatismo, facilismo, consumismo, hedonismo, nihilismo, relativismo, etc., asfixiando la integralidad humana. De modo, que se rechaza la verdad y el reconocimiento objetivo del bien y del mal, y se acaba por no entender una moral acerca del perfeccionamiento del ser humano y de la sociedad con sentido de solidaridad. Este estilo de conducta, vuelve incomprensible al hombre ante sí mismo. Se debe puntualizar que, en estos inicios del siglo XXI, se ha instalado la moda de mencionar a la moral y la práctica de los valores, sin embargo no hay coherencia en lo que respecta a la real vivencia moral y se trata de superar esta situación crítica, que de seguir el descuido generará muchas crisis estorbando el buen desarrollo de la sociedad global.

* Doctora en Filosofía y Ciencias de la Educación por la Universidad Complutense de Madrid. Docente de la UCSS 
Además, como vivimos inmersos en la TV y su estilo de tendencias consumistas que, con frecuencia, desde un primer rechazo se acaba por aceptar con curiosidad y simpatía la imagen de hombre que la TV vende y así muchas veces poco a poco se va considerando normal la inmoralidad que ofrece. Si una ranita se la pone de frente en agua caliente, la rechaza abiertamente, pero si se la pone en una olla y se va subiendo la temperatura queda liquidada, porque poco a poco se acostumbró a lo que le costó la vida a la postre. Igualmente, vivimos en medio del bullicio, con la música pop puesta por lo general con volumen alto como para impedir la comunicación tranquila y la reflexión serena que nos lleva a acostumbrarnos con lo que, en una primera instancia desde nuestra conciencia y la ley humana impresa en el corazón, nos chocó. Asimismo, estamos inmersos en un mundo de Internet que tiene ventajas maravillosas, pero a la vez, se hace presente con sus peligros de aislamiento, inmediatismo y vehemencia frente al trabajo rápido y poco ponderado que apenas consigue alguna madurez en el ejecutor. Todo este panorama complica la comprensión de la moral humana. Finalmente, el sentido de esfuerzo que hay que poner para "ser buena persona» se pierde en la bruma del hedonismo, también en el ámbito universitario que no alcanza a vacunar su desempeño de artificialidades.

-Podemos así, percatarnos de la crisis humana existente, en cuanto a saber elegir el debido comportamiento humano.

-Equivale a decir que, la cultura y moral light, se han instalado en la sociedad actual, e impiden un auténtico desarrollo humano.

La comprensión de la vida humana se pierde en diversos antojos del momento, pues cuesta mucho aceptar en el día de hoy, obrar según una realidad superior a sí, incluso reconocer una realidad superior a la propia razón, notar cómo bien enseñaba San Agustín, «Dios es más íntimo a uno mismo que uno mismo»; pues es el Guía, Creador y Salvador del hombre, razón de su mundo interior y exterior, referente para el comportamiento 
humano ético. No reconocer al hombre y no trascender a Dios merma la posibilidad de realización moral.

Ciertamente, cuando se imponen el relativismo, consumismo, materialismo, nihilismo, y múltiples reduccionismos sobre la concepción del ser humano, de sus acciones como de su comportamiento; y con mayor razón la evasión por las preguntas esenciales sobre la vida humana, su origen y destino junto con la moda de no admitir a Dios en la vida de los seres humanos para que así, cada ser humano sea el único referente absoluto de su vida, ponen a la ética al margen de la vida y por ende, lejos de poder ser enseñada con rigor universitario y responsabilidad social.

Ahondemos como en realidad se ha dado paso a la instalación de múltiples reduccionismos sobre la conducta humana, se ha otorgado más importancia a la apariencia y riqueza externa que a la riqueza interna. Se ha reemplazado, el sentido de esfuerzo, por el facilismo que erradica la reflexión, se ha permitido la instalación del nihilismo que deja al hombre cerrado ante la apertura de la fe. Por esto, la tarea de la madurez y el liderazgo humano se han convertido en una realidad de signos exteriores sin entender la vida interior con toda su riqueza moral. Y justamente la Universidad es la institución indicada para las honduras en el conocimiento.

Digámoslo con claridad y de modo sintético: «con demasiada generalidad los ciudadanos de este mundo global, quieren conducirse en función del "predominio de lo material" y desde este afán de culto por lo exterior, no se puede captar "la idoneidad moral" ni entender la preeminencia por el "afán moral, que tiene su reino y dinámica de procedencia y punto de sosiego en el interior del ser humano».

Se impone así el «vacío existencial» por lo mismo que no se entiende ni al ser humano ni la moral que le compete, en su dimensión esencial de engrandecimiento para el ser humano y su noble conducta. Realmente, es toda una confusión la búsqueda confusa de la «libertad sin compromisos» en una sociedad que se va alienando y adocenando a la influencia de los Medios de Comunicación como si la propia razón no tuviese capacidad de raciocinio y se careciese de una inteligencia con juicio veritativo capaz de distinguir 
entre la verdad y la falsedad e interesarse en el esfuerzo y amor por la verdad auténtica, reemplazando el valor de la verdad por el de la opinión; acabando por darle al subjetivismo y relativismo, el lugar del papel rector para las conductas humanas en la actualidad, lo que puede catapultar el cometido universitario.
-La confusa comprensión de la ética, se supera al entender que en nuestro tiempo, el mismo hombre es un desconocido para sí y para los otros.
-Hay que resolver el conocimiento del ser humano sobre sí.
-De hecho, entender a la especie humana y sus actos, es entender a la ética.
-Así, la ética es para el hombre del siglo XXI un caudal de beneficios.

No obstante, la degradación humana junto al rechazo actitudinal de la buena moral, por parte de la sociedad humana y de la peruana en particular, es susceptible en tanto humana de ser mejorada, justamente por una buena comprensión y decisión de comprometerse con la ética dentro de un realismo antropológico no de ideologías sino según la misma experiencia humana. Se trata de encargarse de suscitar cambios que pueden transformar vidas y así sociedades y naciones para poder globalizar la solidaridad según un reciente llamado de Benedicto XVI. Por ejemplo, desde el sector justicia de cada país, se puede hacer mucho bien o mal, según se efectúe una honesta o deshonesta realización en la elaboración y ejecución de leyes, de esta rectitud depende el destino de las personas. Por eso, la Universidad debe poner al hombre delante de sí mismo con toda la posibilidad de un comportamiento moral no de finta, sino primero por su propia dignidad.

Sinceramente, hay que suscitar el comportamiento de no aceptar, que la verdad y el bien sean instrumentalizados y la objetividad de los valores sea concebida dentro de un relativismo generalizado que no admite la verdad 


\section{LA EDUCACIÓN ÉTICA EN EL SIGLO XXI}

universal. Cada persona puede hacer la experiencia práctica concreta de cambios de costumbres negativas y destructivas por otros comportamientos positivos y constructivos. Como, por ejemplo, un fumador compulsivo puede abandonar tal comportamiento y un estafador inescrupuloso dejar de serlo. El ser humano siempre puede humanizarse y humanizar el mundo desde la aceptación de una moral atenta a la ley natural, por lo tanto con apertura y respeto a Dios y a la persona humana, como un compromiso inmerso dentro del avance que se debe propiciar desde la Universidad para asegurar un desarrollo solidario que impulse paz con ecología. 